\begin{abstract}
s
became worse with signs of intracranial involvement, and three weeks later the patient died.

The autopsy showed purulent meningitis with pus in the right sphenoidal sinus, in both cavernous sinuses, and in the intercavernous sinus. In addition, there was an enlargement of the spleen, acute hæmorrhagic nephritis and hypostatic pneumonia.

Erosion of the Internal Carotid Artery as a result of a Retropharyngeal Abscess. Death from HæmorrhageL. Hofmann.-Boy, aged 2, became ill on the 18 th December I 927 , with a temperature of $40^{\circ} \mathrm{C}$. After some days swelling occurred in the cervical lymphatic glands.

On 27 th December he was admitted to hospital with blood-stained purulent secretion from the nose.

On 2 gth December, otitis media with spontaneous perforation of the right tympanic membrane $t \_o k$ place; a fluctuant swelling in connection with the cervical glands on the right side was incised, and thin pus evacuated; examination of this showed streptococci.

3 rd January 1928, a fluctuant submental swelling was incised.

7 th January a retropharyngeal abscess was found.

gth January, sudden profuse hæmorrhage took place from the mouth and nose with death in a few minutes.

Autopsy showed purulent infection of the cervical glands on both sides with necrosis of the surrounding parts, and an erosion of the left internal carotid artery.
\end{abstract}

\title{
ABSTRACTS
}

THE EAR

Suture of the Facial Nerve within the Temporal Bone. SrerLING BrUnNell, San Francisco. (Surgery, Gynacology and Obstetrics, July r 927 , Vol. xlv., No. r.)

The author reviews the established operative methods for restora-

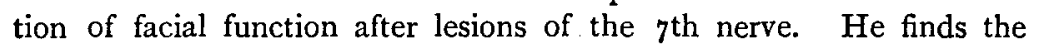
results dissatisfying, in that full function is never regained, and urges that direct end-to-end suture of the divided nerve should be the first resort in traumatic lesions. The descending part of the facial nerve is most suitable for this attempt, and he records a successful case.

His patient was a man, 29 years of age, who seven months previously developed complete facial paralysis immediately after an operation for subacute mastoiditis. The paralysis persisted. After suture of the divided nerve, function began to return in six months, and seventeen 820 


\section{The Ear}

months after operation the patient had regained full voluntary and emotional movements.

At operation he excised the mastoid scar extending his incision two inches downwards. After deepening the mastoid excavation, the lateral sinus, which had been exposed at the previous operation, came into view. Adherent to its wall was the neuroma of the proximal end of the cut nerve. This terminated at a point $6 \mathrm{~mm}$. below the bend of the facial canal, the point of division being immediately behind the pyramid, at the level of the mid-point of the posterior wall of the middle-ear. The facial canal was then laid open from the genu to the stylomastoid foramen. The attenuated distal end of the nerve was densely adherent to the wall of the canal at a point $5 \mathrm{~mm}$. below the proximal neuroma. This was freed. The anterior wall of the mastoid and part of the vaginal plate were removed, and the facial fibres as they entered the parotid gland were freed by a probe. The nerve fibres to the stylohyoid and posterior belly of the digastric were still holding the nerve, so they were divided. $4 \mathrm{~mm}$. of the neuroma and a small amount of the distal end were sacrificed to obtain good nerve-bundles, and, by bringing the distal end of the nerve direct from the parotid gland to the middle-ear, the nerve was joined without tension by four silk sutures passed through the nerve sheath.

A pedicle strip of the sternomastoid muscle $2 \frac{1}{4}$ inches long was used to cover the nerve suture and fill the concavity. The wound was closed.

Function first returned, after six months, in the orbicularis oculi, and after seventeen months the patient had full voluntary and emotional movement in the face. The frontalis muscle alone had not fully recovered its power.

Experience in suturing small nerves is necessary, and the author suggests using a section of the sural nerve of the calf to bridge the gap if the nerve-ends cannot be approximated without tension.

The photographs of the patient are convincing. There is no bibliography.

W. Stirk Adams.

Circulation of the Endolymph. STACy R. Gould. (Laryngoscope, Vol. xxxvii., No. 9, p. 649.)

With the object of determining the nature of the flow of endolymph, experiments were conducted on guinea-pigs. By means of a dental reamer, minute holes were punctured through the external wall of the cochlear duct. In the guinea-pig, the width of the external wall of the cochlear duct is approximately $0.4 \mathrm{~mm}$. in the lower turns. It was possible to open into the cochlear duct without breaking through into either scala vestibuli or scala tympani. Glass capillary tubes were used voL. XLIII. NO. XI. 


\begin{abstract}
s
for the injections of the fluid which was a mixture of equal parts of potassium ferrocyanide and iron ammonium citrate in aqueous solution. A I per cent. solution was used in most of the experiments and the animals were killed at intervals of from forty-five minutes to forty hours after injection. Fixation was by so or 20 per cent. formalin, to which was added either $\mathbf{I}$ or $\mathbf{2}$ per cent. hydrochloric acid to cause precipitation of ferric ferrocyanide (prussian blue) from the injected fluid. Serial sections were made parallel to the modiolar axis of the cochlea. Carmine was selected for staining.

The most striking fact observed was the presence of prussian blue granules not only in the lumen of the saccus endolymphaticus, but also in a certain part of its epithelial wall, the so-called "pars intermedia of the saccus endolymphaticus proprius." It was obvious that the injection fluid passed from the ductus cochlearis through the canalis reuniens into the sacculus and from this through the ductus endolymphaticus into the saccus endolymphaticus, where it had passed into the wall of a portion which is morphologically differentiated from the rest of the membranous labyrinth. It is probable that the injected fluid was passing through the wall, rather than simply into it.

The flow of endolymph in the guinea-pig then, is from the cochlear duct towards the endolymphatic sac, viâ the intervening parts of the membranous labyrinth. The wall of the pars intermedia of the saccus is a region of outflow of endolymph; red blood cells from the hæmorrhage at the injection site were frequently found in the saccus; they could not have reached this without a flow of endolymph.

It may be deduced that endolymph is formed by the stria vascularis of the cochlear duct, and that it flows towards the basal end and through the canalis reuniens into the sacculus and from this through the ductus lymphaticus into the saccus endolymphaticus; it leaves the membranous labyrinth by passing through the wall of the pars intermedia of the saccus into the numerous small blood-vessels of this region.
\end{abstract}

\title{
ANDREW Campbell.
}

\section{The Auditory Reaction to the Galvanic Current: Test of Truthfulness in Medico-Legal Examinations. J. Ramadier. (Annales des Maladies de POreille, du Larynx, du Nez et du Pharynx, December 1927.)}

Of the three labyrinthine reactions to the galvanic current, viz., nystagmus, movements of the head and trunk, and the auditory reaction, the latter has certainly been the least studied. It consists of a particular noise in the ear when the latter is subjected to the "make" or "break" of a galvanic current.

The writer describes this reaction fully and then explains the different methods employed in eliciting and studying it, first in the 


\section{The Ear}

normal person and then in those suffering from the various otopathies. From his examinations the writer draws the following conclusions :-

(I) The auditory reaction to the galvanic current is relatively rare (35 per cent.) in subjects exempt from every otopathy and every affection of the central nervous system.

(2) It is appreciably more frequent and early in the group of lesions affecting the conduction apparatus, and especially in their acute processes (moderate hyperexcitability).

(3) It is constant and appears very early and with remarkable intensity in the labyrinthine lesions proper (strong hyperexcitability).

(4) It is inconstant, and when it exists, it shows a variable intensity in those lesions of the apparatus of perception where one cannot determine conclusively the situation between the labyrinth and the centre of the cochlear nerve.

As a means of testing the truthfulness of a person subjected to a medico-legal examination the reaction to the galvanic current will be found of use. Its appearance in a person complaining of an important deafness, and still more the appearance of an exaggerated reaction, allows one to exclude both the hypothesis of simulation as well as that of functional deafness.

L. Graham Brown.

\section{Paraphenylene-Diamine Labyrinthitis. E. Watson-Williams. (Lancet, I928, Vol. i., p. II23.)}

The author states that this drug, the essential ingredient in several hair "restorers" and liable to cause dermatitis, appears to have a selective action on the labyrinth. Attention has already been drawn to this action by Laurens, in France. The author describes a case in a lady, aged 33, with obscure vertigo. The diagnosis was reached by noting a rash on the neck. A fur collar, frequently worn, was found to contain paraphenylene-diamine in demonstrable quantity. Avoidance of dyed fur and attention to the bowels banished both rash and vertigo.

MACLEOD YEARSLEY.

Influence of the Cervical Sympathetic on the Reaction of Nystagmus.

Prof. Umberto Luigo Torrini. (Archivio Italiano di Otologia,

Vol. xxxviii., fasc. 12, Dec. 1927.)

A number of experiments have been performed on the caloric reaction of the ears of rabbits and guinea-pigs. Repeated experiments gave quite different results, and the observer found that during syringing the lumen of the external meatus varied owing to muscular 


\section{Abstracts}

contractions. He overcame this difficulty by making an incision into the wide deeper part of the meatus-the bulla-and injecting the fluid into this space, when he obtained consistent results. In a number of cases the cervical sympathetic trunk was cut or the superior ganglion removed and further tests carried out. The results of these were irregular, but generally speaking, the duration of irrigation required to produce nystagmus was less, and the amount of water used was less after sympathectomy. The duration of nystagmus after the operation was in some cases increased and in some cases decreased.

These results suggest that the action of the sympathetic system has some influence on the production of nystagmus, and further understanding of this may seriously challenge the theories of Bárány.

F. C. ORMEROD.

\section{Rotation Nystagmus as affected by Different Experimental Conditions, and the Significance of the Contralateral Connective Tracts of the Vestibular Nerve. W. UNDRITz, Leningrad. (Zeitschrift fuir Hals-, Nasen-, und Ohrenheilkunde, Band xix., Heft 5.)}

With the kymograph fixed on the rotating platform, nystagmus could be demonstrated even with very limited degrees of rotation. The minimum rapidity required for horizontal nystagmus was an angular movement through $3^{\circ}$ per second. With increased rapidity the tonic contraction of the eye-muscles increased, the jerks being smaller and more frequent. The effect of vision on the nystagmus is in the rabbit extremely slight, but in the human subject it increases the nystagmus during rotation and checks the post-nystagmus.

Rotation in the frontal planes was affected with the head bent forwards through $90^{\circ}$. After the usual ro rotations in twenty seconds a pause of, say, five seconds, was allowed and the head was then suddenly raised, when the reaction was noted. This was generally a tendency to fall in the frontal plane, in spite of the sagittal movement of the head, and was therefore attributed to the otolith apparatus.

The influence of the contralateral connecting tracts was tested by means of a perfectly central sagittal incision made with de Kleijn's special knife in the floor of the fourth ventricle, from the level of the abducens to that of the acusticus. It was then impossible to induce typical nystagmus. If the incision was a little to one side of the middle line spontaneous nystagmus towards that side took place after an interval. During the interval the slow component could be induced by caloric or rotation stimuli. The spontaneous nystagmus could be influenced, i.e. checked to a considerable extent by appropriate "calorisation." The contralateral vestibular fibres are, therefore, indispensable for the production of typical nystagmus.

James Dundas-Grant. 


\section{The Nose and Accessory Sinuses}

Vestibular Rotational Nystagmus Tracings Improved. J. Онм., Bottrop. (Zeitschrift für Hals-, Nasen-, und Ohrenheilkunde, Band xix., Heft 5.)

This observer, an ophthalmologist, has already contributed articles on nystagmometry especially in relation to miners' nystagmus, and has emphasised the importance of testing the nystagmus with the eyes shut and in a pitch-dark room. His former tracings were, in his opinion, distorted by the unsteadiness of the registering lever, but they have been made more perfect by lengthening the lever and weighting it, as in the new nystagmograph described in Graefe's Arch. für Ophthalm., vol. cxix. He gives tracings taken with the instrument for comparison with those of the same cases taken with the old one, to be found in Band xvii. of this Zeitschrift, p. 263. In such experiments the patient was submitted to two rotations. With open eyes and in a light room a mixture of optical and vestibular nystagmus was followed only in a few cases by any after-nystagmus, but with closed eyes and in darkness, after-nystagmus was the rule, though slower and of less amplitude than the nystagmus during rotation.

James Dundas-Grant.

The Influence of Sight on Vestibular Rotational Nystagmus and AfterNystagmus. Third Communication. J. Oнм., Bottrop. (Zeitschrift für Hals-, Nasen-, und Ohrenheilkunde, Band xix., Heft 2, p. 87.)

Professor Ohm, as an ophthalmologist, has drawn attention to the contention between ocular and vestibular nystagmus during rotation if the eyes are not completely blinded or the room not pitch-dark. $\mathrm{He}$ therefore renews his plea for nystagmography, the eyes being closed and the room pitch dark, the nystagmic movements being registered on a revolving drum. He also advocates the trial of optical nystagmus, but considers that the "inversion" of spontaneous nystagmus by the optical nystagmus induced by the revolving black-and-white drum does not prove the non-labyrinthine origin of the existing nystagmus as claimed by Demetriades.

This paper ought to be read in connection with the writer's previous articles on the same subject. James Dundas-Grant.

THE NOSE AND ACCESSORY SINUSES.

Conservative Septum Operations. N. A. PAUTow, Leningrad. (Zeitschrift für Hals-, Nasen-, und Ohrenheilkunde, Band xix., Heft 3.)

To obviate the flapping of the septum when complete radical submucous resection is carried out, Pautow recommends Wojatschek's plan of detaching the cartilage from one side only and resecting such 


\section{Abstracts}

portions only as are necessary to permit of restoration. In his experience portions of cartilage replaced after removal break down and become absorbed.

JaMES Dundas-Grant.

\section{A Case of Nasal Tuberculosis. Givlio Cesare Antognoli, Rome. (Archivii Italiani di Laringologia, Anno xlvi., Fasc. 4, August I927.)}

The author remarks on the comparative rarity of tuberculosis in contrast with the frequency of lupus. The course of the disease is very slow and Giorgio Ferreri recorded a case of nasal tuberculosis where the inferior turbinal became completely calcified, but this was an unusual case.

The treatment of nasal tuberculosis has included the application of lactic acid, iodoform, iodine, X-rays, radium, Finsen light, heliotherapy and galvanocautery.

The author records the case of a girl of fifteen in whom there was a perforation of the anterior part of the cartilaginous septum about the size of a sixpence. The anterior margin was scarred and healed, but the posterior was covered with soft, pale-red granulations which bled very readily. These granulations spread into the nasal fossæ on either side and obstructed the nose. Portions of the tissue were examined microscopically and showed typical tubercles and areas of necrosis. Hæmorrhages from this region were solfrequent and profuse and so easily excited that it was found impossible to treat the lesion by any of the usual local applications or by galvanocautery and it was decided to use diathermy at intervals of ten to fifteen days. The granulation shrunk rapidly and the hæmorrhages grew fewer and fewer. Investigation of the blood showed that the clotting time was somewhat prolonged and though the case was not one of true hæmophilia there was a distinct tendency to bleeding. This was treated by administration of blood serum and was very much improved thereby, helping on considerably the treatment of the tuberculosis. F. C. Ormerod.

Cholesteatoma of the Nasal Accessory Cavities : its Origin and Conditions for Development. A. LAUTENSchläGer, Berlin. (Zeitschrift für Hals-, Nasen-, und Ohrenheilkunde, Band xix., Heft 3, p. 286.)

This was found most highly developed in cases in which the antrum after wide radical operation through the mouth was lined, as far as possible, with a skin-graft from the thigh. It occurs occasionally in the frontal sinus after traumatic or other opening, when the pavement epithelium of the forehead may proliferate inwards and displace the columnar epithelium of the original mucous lining. Besides this expropriating action, the cholesteatoma matrix is credited, like certain 826 


\section{The Nose and Accessory Sinuses}

lipoids, with a faculty of digesting, which is more marked on bone than on fibrous tissues. It also exercises pressure, especially under the influence of moisture. Primary cholesteatoma of the adnexa is extremely rare but appears to exist. Lautenschläger does not believe in metaplasia of epithelium as an explanation. In regard to treatment he recommends clearing out the masses with conservation of the matrix and establishment of a free opening for contact with the outer air.

James Dundas-Grant.

The Technique of the Operative Opening of the Frontal Sinuses. A. Putschkowsky, Kiew. (Acta Oto-Laryngologica, Vol. xi., Fasc. 4.)

The methods of operating upon the frontal sinus are reviewed. The author believes that the intranasal operations, e.g. Winkler and Halle, are now seldom used. He points out the disadvantages of the various external operations, but he himseif describes a method coming under the group of osteoplastic operations, a combined operation founded upon the methods of Golowin and Jansen. It is possible in most cases to avoid all disfigurement, and at the same time every possibility is afforded of removing the mucous membrane of the frontal sinus and the diseased ethmoid cells.

The operation is carried out as follows:-The chief incision runs along the fold of the corrugator supercilii muscle from 2.5 to 3 centimetres above the inner angle of the eyebrow down to the inner angle of the eyebrow, cutting through this and proceeding as in Killian's operation along the side wall of the nose. A second incision 4 to 4.5 centimeters long runs along the lower edge of the eyebrow to meet the first incision at the inner angle. The triangular flap of soft tissues is then turned upwards and outwards. An osteoplastic flap from the front wall of the sinus is then turned downwards with the periosteum as a hinge. This opening gives access to the upper part of the sinus. The remainder of the operation deals with the floor of the sinus, the duct, the ethmoid and, if necessary, the sphenoidal sinus as in Killian's operation.

The osteoplastic flap is then restored to its place; a drain is passed into the nose, and the soft parts sewn up. H. V. Forster.

Sphenoidal Sinusitis with Peculiar and Unique Symptoms. ROBERT F. Ridpath. (Laryngoscope, Vol. xxxvii., No. 12, p. 880.)

Sphenoidal sinusitis is divided into two classes, acute and chronic, and the latter is subdivided into those with free drainage and those with deficient drainage.

The symptoms of acute sphenoidal sinusitis are as follows:- $(a)$ Pain, which may be divided into headache and reflex or toxic 827 


\section{Abstracts}

manifestation; also vacuum headache is often present. Headache is mainly occipital, while reflex pain may extend over the mastoid and temporal regions, frequently accompanied by muscular stiffness in the neck. Pain may be felt over the canine tooth on the side affected, or a pain of a burning character or continuous stab may be experienced in the region of the supratonsillar fossa. Behind the eye the pain is usually dull in character and assumes a feeling of pressure from behind forward and this is not increased by pressure on the eyeball. Scintillating scotoma is a frequent and often a prodromal symptom. (b) Vertigo is often present either continuous or interrupted in nature, whether in recumbent or erect posture. Stooping forward or rapid movement of the head may produce giddiness which may cause a fall. While walking, the buildings appear to lean towards the centre of the street, and patients having this symptom walk towards the curb, and have difficulty in keeping a straight line. (c) Sleeplessness; the majority of sufferers are unable to sleep in comfort; a feeling of something breaking and discharging into the throat is characteristic of sphenoidal discharges. Objective symptoms are few; discharge may or may not be observed; a temperature of $99.5^{\circ} \mathrm{F}$. to ror $.5^{\circ} \mathrm{F}$. is usual.

In chronic sphenoidal infection the subjective, objective, and toxic symptoms are subdivided into several groups.

Subjective symptoms may show themselves as (a) pressure symptoms, headache radiating in the same manner as in the acute variety. (b) Mental symptoms and (c) toxic symptoms may be considered together, such as loss of memory, depression, lack of concentration, and vertigo with stiffness of neck muscles. Pain in the canine tooth, glossopharyngeus muscle, over the instep, and tinnitus aurium are less frequent, but may be the only diagnostic factor.

(d) Ocular symptoms; sudden blindness, unilateral as a rule; exophthalmos may be present; scintillating scotoma and diplopia are frequent manifestations; in one case polyopia of seven images was the outstanding feature; $(e)$ olfactory disturbances such as diminution or loss of smell may be present; $(f)$ general symptoms, such as sore throat, cough, aphonia, gastric disturbances are often met with, hepatic and gall-bladder infection with a yellow-coloured soft palate are frequently observed.

The non-aeration or negative pressure type of sinusitis is in the author's experience the most virulent of all. It is possible that nonaerobic germs (which are the most virulent) may be responsible for the symptoms, which is overcome by aeration as a result of operation.

Six case reports are appended, illustrating some of the symptoms described. The article should be read in the original.

\section{ANDREW CAMPBELL.}




\section{The Nasopharynx}

\section{THE NASOPHARYNX}

Adenoid Vegetations in Adults. F. DE Swiezynoki. (Annales des Maladies de POreille, du Larynx, du Nez, et du Pharynx, March 1928.)

Since various authors show so much divergence of opinion on this subject, the writer has made an independent inquiry, using for his observations $35^{\circ}$ soldiers between the ages of 21 and 23 .

He draws the following conclusions :-

(I) Adenoids are a frequent phenomenon in adults over the age of 20 years, affecting 34 per cent., and in them they are sufficiently large in 20 per cent. to require removal.

(2) The greatest number (39 per cent.) were found in ear, nose and throat cases.

(3) There is reason to believe that the presence of adenoids in adults denotes a symptom of an endocrine disturbance of the sexual glands or the hypophysis.

(4) In adults with adenoids the high-arched palate is found to be present twice as often as in those without vegetations.

L. Graham Brown.

\section{Chronic Rhinopharyngeal Disease. Dr ShIRLEy, Detroit. (Surgery, Gynacology and Obstetrics, June 1927.)}

The author puts forward the view that nasal obstruction has farreaching consequences, and instances Cushing's experiments showing that urotropine injected into the rectum appears in the ventriculospinal system in one and a half to three minutes; he suggests that local infections in the nose must be viewed in the same light.

The remote influence of nasal obstruction on the organism is referred to in the results of animal experiments by Anderson of the Detroit School of Medicine, in which a series of one hundred guineapigs, rabbits and dogs were subjected to partial or complete occlusion of the nostrils. He found that nasal obstruction led to death or serious impairment of vitality; local disease of the respiratory tract was induced, dilatation of the heart, changes in the skin and blood, and symptoms resembling asthma and emphysema often occurred with histological change.

Reopening the occluded nostrils was followed by prompt disappearance of the symptoms. The author has found a successful treatment for "lymphoid" children with nasal infection in compressing two potatoes, carrots, beet, tomatoes, and a bunch of celery in a meat press, and giving a wineglassful of the extract with each meal.

He regards the American method of life in a centrally heated 


\section{Abstracts}

house, alternating with periods of excessive cold out of doors, as placing undue stress on the nasal mucosa, and looks forward to a more rational upbringing for the Caucasian child. The problem of nasopharyngeal disease, he feels, will be solved by an addition to our knowledge of immunity.

S. Adams.

\section{THE PHARYNX.}

Post-operative Tonsillar Hamorrhage due to the Organisms of Vincent: Report of Five Cases. Albert P. Tibbets. (Laryngoscope, Vol. xxxvii., No. I 2.)

Post-operative hæmorrhage from the tonsil bed as a result of infection by the organism of Vincent's angina is a rare occurrence. Five such cases have been observed in the last two years and early recognition is extremely important as the treatment is essentially different from that usually employed for post-operative hæmorrhage.

All the cases observed suffered from similar symptoms before operation, frequent tonsillitis and soreness with discomfort in the throat following the least exposure to cold and damp. All were slightly underweight, anæmic, easily tired, suffered from muscular pains and complained of excessive mucus from the upper air passages. An attack of tonsillitis caused severe prostration.

Post-operative symptoms also showed a similarity, in that there was severe pain on the day before bleeding took place, which varied from two to seven days. The hæmorrhage came on suddenly, without apparent cause. The blood clotted readily, but there was a steady trickle from below the clot. In all cases there was a tendency to a spontaneous arrest at one point while it broke out at another. After removal of clots, numerous brownish elevated spots about $3 \mathrm{~mm}$. in diameter could be seen in pale contrast to the floor of the fossa. On manipulation these spots would break down and bleed sharply for a few moments. It would stop spontaneously at one point and break out at another. On attempting to seize the points with hæmostats it was seen that the tissues were necrotic. The edges of the pillars and soft palate became involved in a shallow ulceration which bled freely. In all cases both the spirillum and fusiform bacilli were recovered in sufficient numbers on direct smear to leave no doubt of the specific cause of the hæmorrhage.

There were no fatalities in the series. Once appropriate treatment is applied, improvement is rapid and healing takes place in two weeks.

The most effective treatment after cleansing the fossa of clot, consisted in firm pressure with a gauze sponge soaked in pure hydrogen peroxide. A string sponge moistened with the same solution is placed 


\section{The Pharynx}

in the fossa and left for several hours. On removal the fossa is painted with ro per cent. solution of neoarsphenamine in glycerine every four hours. Every two hours the throat is gargled with 50 per cent. solution of hydrogen peroxide followed by a half-saturated solution of sodium perborate. Under this treatment the patient's mental and physical condition improved in a remarkable manner.

The five cases are described in detail and form an illustrative study of a complication which might give cause for serious alarm if not recognised.

ANDREW CaMpBell.

Rheumatism, Tonsils, and Glands. K. D. WILKINson and A. G. Ogilvie. (Lancet, 1928, Vol. i., 647.)

The authors conclude in an inquiry into the relation of tonsils and enlarged glands to cardiac disease in rheumatic children, that chronic infection of the tonsils is commonly associated with rheumatism and chorea in children, and frequently causes enlargement of the glands at the angle of the jaw. Children who have rheumatism are less likely to develop cardiac disease if the tonsils are completely removed, and in such children tonsillectomy results in the disappearance of the enlarged glands in over 70 per cent. of cases. While the enlargement of the glands may be taken as an absolute indication for the removal of the tonsils in rheumatic children, it is probable that, in order to obtain the best possible cardiac results, tonsillectomy ought to be performed before the glands become enlarged.

Macleod Yearsley.

Tonsillectomy in Adult Patients. Geo. C. CathCart, M.A., M.D. (Practitioner, December 1927. )

Conditions for which the author has frequently removed tonsils include, in addition to the more common rheumatic and neuritic indications, chronic inflammation of the eyes and eyelids, goitre, tachycardia, persistent nasal discharge after operation on the sinuses, persistent ear discharge after the radical mastoid operation, chronic eczema, recurring boils, anæmia, and colitis.

To determine the question of sepsis, the tonsil should be examined by squeezing it with the aid of two spatulæ. The author finds that in patients whose chief complaint is that of being "always tired" a swab taken of the pus extracted from the massaged tonsil always contains a large percentage of long-chained hæmolytic streptococci.

The position and method of operation described varies only in small details from the usual procedure of dissection under general anæsthesia.

T. Ritchie Rodger. 


\section{Abstracts}

\section{THE LARYNX.}

Notes on Laryngeal Tuberculosis. End-Results of Active Treatment.

Dr Frey. (Annales des Maladies de l'Oreille, du Larynx, du Nez, et du Pharynx, March 1928).

Active intervention on the tuberculous larynx, chiefly by means of the galvano-cautery, is not always indicated, and is a question to be decided by the specialist, only from his own clinical experience.

Thus in a summary of $\mathrm{x} 20$ cases presenting all degrees of laryngeal and pulmonary lesions, the writer expresses his results as follows: 72 cases were of such a nature as not to warrant any surgical interference on the larynx. The condition of the remaining 48 , however, admitted of an active form of treatment being undertaken. Of these, 8 cases gave no beneficial result, 20 were improved and 20 were cured.

The lesson to be gained from these observations is, that in a very large number of cases treatment of the larynx can have only a palliative value, the clinical picture being dominated by the progressive evolution of the pulmonary lesions. In the great majority of cases it is in the region of the lung and not of the larynx that the question of life and death is to be decided.

Nevertheless, even when this treatment is undertaken merely as a palliative measure, it is of undoubted value in its indirect beneficial action on the pulmonary, general and mental condition of the patient.

L. Graham Brown.

The Systematic Examination of the Larynx in Cases of Pulmonary Tuberculosis. Dr FERRando. (Annales des Maladies de l'Oreille, du Larynx, du Nez, et du Pharynx, March 1928).

Once again our attention is drawn to the importance of examining the larynx in every patient suffering from pulmonary tuberculosis.

From the advantages gained in superintending the laryngological department of a large tuberculous clinic at Barcelona the writer is enabled to give very detailed statistics of several thousands of cases examined. Thus he found that the incidence of definite tuberculous lesions in the larynx was 26.25 per cent. Classifying the lesions into three groups, viz., initial, intermediate and severe, he gives further statistics for these groups and for the particular regions of the larynx affected. He deduces etiological and pathological facts regarding the sex and age incidence of the disease, the predisposing influence of the various professions, and also the relationship between the type of pulmonary lesion (e.g. fibrous, caseous, etc.) and the frequency of laryngeal complication. He points out the important fact that in early cases the larynx may be affected without giving rise to any functional disturbance of this organ. Finally he affirms that in all his observations he has never yet met with a primary laryngeal tuberculous lesion.

L. Graham Brown. 


\title{
Reviews of Books
}

\section{MISCELLANEOUS}

\author{
Ephedrine and Ephetonin. R. CuRTIS. (Lancet, 1928, Vol. ii.)
}

The author gives a summary of his investigations at the Department of Physiology in the University of London. Both drugs are now being fairly extensively used for asthma, giving more prolonged results than adrenalin. Ephedrine is the principle of Ma Huang (ephedra vulgaris), while ephetonin is a synthetic product. The experimental evidence submitted shows that ephedrine is approximately twice as active as ephetonin.

Macleod Yearsley.

Diphitheria Carriers. W. C. HARveY. (Lancet, 1928, Vol. ii.)

The writer gives results of his research into all the carriers from the Metropolitan Asylums' Board Infectious Hospitals, collected for investigation in the North-Eastern Hospital. His conclusions are as follows: The most important carrier is he who harbours diphtheria bacilli in the nose, and the only satisfactory form of treatment is douching with a mildly alkaline nasal douche. When the bacilli are confined to the throat, tonsillectomy gives very satisfactory results. The ear carrier is uncommon, very difficult to treat, and does not respond readily to treatment. The treatment of diphtheria carriers should mainly consist in rectifying local abnormalities and pathological conditions responsible for the carrier state. If this is done properly the coexistent abundant flora will be diminished, and the diphtheria bacillus will also probably disappear.

Macleod Yearsley.

\section{REVIEWS OF BOOKS}

The Medical Annual: A Year-Book of Treatment and Practitioner's Index. Forty-sixth year. 1928. Bristol: John Wright \& Sons, Ltd. London: Simpkin, Marshall, Hamilton, Kent \& Co., Ltd. Price 2 Is.

Of the Medical Annual as of Cleopatra it may be said "age cannot wither, nor custom stale, her infinite variety." The editor in his introduction strikes a singularly happy note with regard to the "glorification of research" as a label of some exalted virtue that belonged exclusively to demigods working in laboratories, when he points out that it is to clinical workers that we owe nearly all the progress chronicled in this volume. The contents go to support this contention and to emphasise its appeal to the clinical workers whose

vOL. XLIII. NO. $\mathrm{XI}$.

833

$3 \mathrm{~K}$ 